\title{
当院における腹腔鏡下子宮筋腫核出術後の妊娠に関する検討
}

\author{
慶應義塾大学医学部 産婦人科学教室
}

伊藤嘉佑子、浅田弘法、有馬宏和、西山紘子、古谷正敬、佐藤健二、

内田 浩、浜谷敏生、丸山哲夫、久慈直明、末岡 浩、吉村泰典

\section{Reproductive Outcome following Laparoscopic Myomectomy}

Kayuko Ito, Hironori Asada, Hirokazu Arima, Hiroko Nishiyama,

Masataka Furuya, Kenji Sato, Hiroshi Uchida, Toshio Hamatani,

Tetsuo Maruyama, Naoaki Kuji, Kou Sueoka, Yasunori Yoshimura

Department of Obstetrics and Gynecology, Keio University of Medicine

\begin{abstract}
Compared to myomectomy by laparotomy, laparoscopic myomectomy (LM) results in less postoperative pain and a shorter hospital stay. Furthermore, LM has a particular advantage in that it reduces the risk of postoperative adhesions when pregnancy is desired. We evaluated the reproductive outcomes after LM including the risk factors in subsequent pregnancies. Among the 432 patients who underwent LM in our department between January 2005 and December 2010, 153 patients desired to preserve fertility. Among the 153 patients, 88 patients (58\%) had a total of 107 pregnancies after LM. Of those, 71 pregnancies $(66 \%)$ were spontaneous, 7 pregnancies $(7 \%)$ required intrauterine insemination IUI), and 28 pregnancies $(26 \%)$ required IVF. The mean $( \pm \mathrm{SD})$ age was $36.1 \pm 3.6$ years in the pregnant group (88 patients), and was $38.2 \pm 3.5$ years in the non-pregnant group (65 patients). We found a negative correlation to achieving a pregnancy with patient age at the time of LM (HR: 0.94; $95 \%$ CI: $0.88-0.99 ; P=0.039$ ). The following reproductive outcomes were noted: 58 pregnancies $(91 \%)$ were term deliveries, 6 pregnancies $(9 \%)$ were preterm delivery (from 33 to 36 weeks), 27 pregnancies (28\%) were spontaneous abortions, and one (1\%) was an ectopic pregnancy. Although there was one silent uterine rupture in this study, the location of rupture was not at the site of a uterine scar. It is unclear whether the laparoscopic procedure is associated with the silent uterine rupture. We found that the main factor determining fertility after LM was patient age. Reproductive outcomes are relatively good following LM.
\end{abstract}

Key Words: laparoscopic myomectomy, reproductive outcome

\section{【背景と目的】}

子宮筋腫の有病率は生殖年齢女性の $11.7-23.6 \%^{11}$ と報告されているが、ホルモン依存性に増加する ため年齢とともにその有病率も上昇する。また明 らかに子宮内腔を圧排する場合を除いて、どのよ うな子宮筋腫が不妊に影響を与えるかどうかにつ いては文献により様々で、確立された意見はない2)。 しかし、過多月経や腹満感、頻尿などの症状を有 する場合には子宮筋腫核出術の適応となる。近年
の晚婚化に伴い、子宮筋腫核出術後に妊娠する症 例は増加しており、腹腔鏡手術によるメリットを 生かすため多くの施設で腹腔鏡下子宮筋腫核出術 (Laparoscopic myomecomy: LM) が行われてい る。LM後の妊娠予後についての報告は徐々に増 え、その安全性は確立されつつある ${ }^{3,4)}$ 。しかし頻 度は低いながらもLM後の妊娠における子宮破裂 の報告も散見され ${ }^{5)}$ 、慎重な妊娠・分娩管理が必 要と考えられる。

今回我々は当院におけるLM後妊娠について妊 
娠に影響する因子や妊娠予後について検討するこ とを目的とした。

\section{【対象と方法】}

2005年 1 月から 2010 年 12 月の 6 年間に当院で腹 腔鏡下子宮筋腫核出術（LM）を施行した432例 のうち、挙児希望のあった153例を対象とし、後 方視的検討を行った。手術適応は有症状（腹部膨 満感、頻尿、過多月経など)、不妊の原因と考元 られる場合（MRIにて内腔圧排像を呈する）とし た。術後半年以上フォローアップできた症例を対 象とし、年齢、核出筋腫個数、核出筋腫重量、手 術時間、子宮内膜症合併率、術前不妊期間、術後 妊娠率、術後妊娠に寄与する因子、妊娠予後など について検討を行った。

統計学的検討は、単変量解析としてMannWhitney解析、 $\chi^{2}$ 解析を行い、多変量解析とし てCox回帰分析を行った。 $\mathrm{P}<0.05$ 統計学的に有 意差ありと判定した。全ての統計解析にはSPSS 18.0を用いた。

LMの基本術式は子宮内にウテリンマニュピレ ーターを挿入し、気腹法により4ポートを配置、 体位は砕石位で10度までの骨盤高位としている。 筋腫と筋層漿膜下に 100 倍希釈したバソプレッシ ンを局注し、ハーモニックスカルペルを使用して 子宮筋層に切開を加え、有銁把持銝子などで筋腫 核を把持牽引し筋腫を核出する。核出後の筋層は その深さに応じて $1 \sim 3$ 層に縫合する。縫合糸は $0 \sim 1$ 号の合成吸収糸を使用しているが、漿膜へ 露出する糸はモノフィラメント糸を使用し、術後 の癒着防止対策としている。また止血目的や卵管 付近の小筋腫などの場合には3-0から4-0合成吸収 糸を使用し、針穴からの出血防止や卵管閉塞予防 に努めている。さらに子宮破裂を防止する目的で、 エネルギーデバイスによる止血が過度にならない よう適宜縫合による止血も行っている。摘出後の 筋腫は腹腔内で細切し、トロッカー創より体外へ 搬出する。また当科でのLMは一人の術者が全て の手術に関わり一定の術式で行われている。

\section{【結果】}

対象153例を妊娠群 $(\mathrm{n}=88)$ と非妊娠群 $(\mathrm{n}=$ 65）にわけ、妊娠に寄与する因子を調べるために 各因子となり得る項目において単変量解析を行っ た (表 1$)$ 。単変量解析では年齢 $(36.1 \pm 3.6$ 歳 vs $38.2 \pm 3.5$ 歳, $p=0.001)$ 、手術時間（166.0 \pm 55.3 分 vs $195.9 \pm 76.0$ 分, $p=0.009$ ）、術前不妊期間（21.3
表 1 妊娠に寄与する因子〜単変量解析〜

\begin{tabular}{|c|c|c|c|}
\hline & $\begin{array}{c}\text { 妊娠 } \mathrm{N}=88 \\
(\text { mean } \pm \text { S.D.) }\end{array}$ & $\begin{array}{c}\text { 非好娠 N=65 } \\
\text { (mean } \pm \text { S.D.) }\end{array}$ & $P$ value \\
\hline 年齢(臓) & $36.1 \pm 3.6$ & $38.2 \pm 3.5$ & 0.001 \\
\hline 手術時間(分) & $166.0 \pm 55.3$ & $195.9 \pm 76.0$ & 0.009 \\
\hline 出血量 (ml) & $227.5 \pm 241.2$ & $309.5 \pm 395.1$ & $>0.05$ \\
\hline 核出筋腫個数 (個) & $4.9 \pm 4.7$ & $4.5 \pm 3.8$ & $>0.05$ \\
\hline 核出最大筋腫径 $(\mathrm{cm})$ & $6.6 \pm 2.2$ & $6.5 \pm 2.1$ & $>0.05$ \\
\hline 核出筋腫重量 (g) & $199.0 \pm 179.1$ & $169.6 \pm 131.2$ & $>0.05$ \\
\hline 術前不好期間(月) & $21.3 \pm 31.9$ & $40.6 \pm 40.0$ & 0.0002 \\
\hline rASRM(点) & $17.1 \pm 24.8$ & $34.7 \pm 35.1$ & $>0.05$ \\
\hline 子宮内膜症性戴胞合併率(\%) & $11.3(10 / 88)$ & $20.0(13 / 65)$ & $>0.05$ \\
\hline 子宮内膜症合併率 (\%) & $32.9(29 / 88)$ & $49.2(32 / 65)$ & 0.042 \\
\hline 卵管周囲癒着合併率(\%) & $17.0(15 / 88)$ & $16.9(11 / 65)$ & $>0.05$ \\
\hline
\end{tabular}

\pm 31.9 ケ月 vs $40.6 \pm 40.0$ ケ月, $\mathrm{p}=0.0002$ ）、子宮内 膜症合併率 $(32.9 \%$ vs $49.2 \%, \mathrm{p}=0.042)$ におい て妊娠群と非妊娠群の間に有意差を認めた。これ ら単変量解析で有意差のあった項目に対して、多 変量解析であるCox回帰分析を行ったところ（表 2 )、年齢が有意に妊娠に寄与していると考えら れた（HR 0.94, 95\%CI 0.88-0.99, p=0.039）。また 術前不妊期間の $\mathrm{p}$ 值は 0.05 以下ではないものの低 值であり、術前不妊期間は妊娠に寄与する傾向が あると考えられた（HR 0.99 95\%CI 0.99-1.00, p= 0.076)。

挙児希望のあった153例のうち、88例が妊娠し、 妊娠率は58\%（88/153）であった。88例のうち 11 例が 2 回妊娠し、 4 例が 3 回妊娠したため、総妊 娠回数は107回であった。また、解析の時点で 5 例が妊娠継続中であった。妊娠形態の内訳は自然

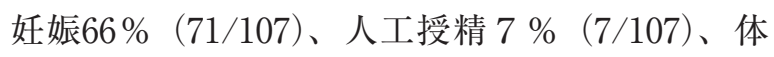
外受精26\%（28/107）、不明 1\%（1/107）であっ た。術後初回妊娠に至までの平均期間は11.8土 11.1 月だった（表 3 )。総妊娠107回のうち妊娠 予後が不明であった10例を除いた 97 妊娠を分母と した場合、自然流産率は28\%（27/97）、異所性妊 娠率は $1 \%$ （1/97）であった。また、総妊娠107 回のうち、妊娠予後が不明であった10例と妊娠継 続中の 5 例を除いた92回の妊娠のうち、生児を獲 得したのは64妊娠であり、生児獲得率は70\% (64/92) だった。この中には 2 回の双胎妊娠が含 まれていたが、1 双胎に対して 1 回の妊娠として

表 2 妊娠に寄与する因子〜多変量解析〜

\begin{tabular}{|c|c|c|c|c|}
\hline & $\begin{array}{c}\text { 妊娠 } N=88 \\
(\text { mean } \pm \text { S.D.) }\end{array}$ & $\begin{array}{c}\text { 非好娠 } \mathrm{N}=65 \\
(\text { mean } \pm \text { S.D. })\end{array}$ & $P$ value & $\begin{array}{c}\mathrm{HR}(95 \% \mathrm{Cl}) \\
\text { (range) }\end{array}$ \\
\hline 年齢(歲) & $36.1 \pm 3.6$ & $38.2 \pm 3.5$ & 0.039 & $0.94(0.88-0.99)$ \\
\hline 手術時間(分) & $166.0 \pm 55.3$ & $195.9 \pm 76.0$ & 0.27 & $1.00(0.99-1.00)$ \\
\hline 術前不妊期間(月) & $29.2 \pm 22.3$ & $45.2 \pm 29.6$ & 0.076 & $0.99(0.99-1.00)$ \\
\hline 子宮内膜症合併率(\%) & $\begin{array}{c}32.9 \\
(29 / 88)\end{array}$ & $\begin{array}{c}49.2 \\
(32 / 65)\end{array}$ & 0.47 & $0.84(0.53-1.34)$ \\
\hline
\end{tabular}




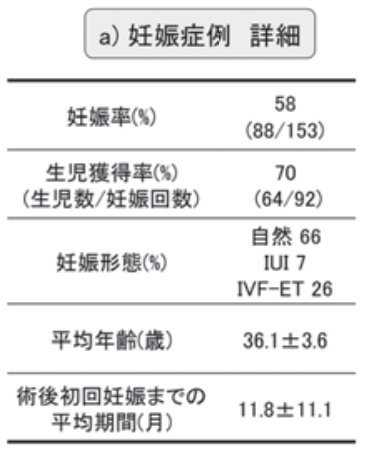

\begin{tabular}{|c|c|c|}
\hline & $\begin{array}{l}\begin{array}{l}\text { 妊娠数 } \\
(n=107)\end{array} \\
\end{array}$ & 割合 (\%) \\
\hline 自然流産 & 27 & $\begin{array}{c}28 \\
(27 / 97) \\
\end{array}$ \\
\hline 異所性娃娠 & 1 & $\begin{array}{c}1 \\
(1 / 97) \\
\end{array}$ \\
\hline 分婏 & 64 & $\begin{array}{c}70 \\
(2 / 92) \\
\end{array}$ \\
\hline 妊娠継続中 & 5 & \\
\hline 不明 & 10 & \\
\hline
\end{tabular}

表 4 周産期予後と分娩方法

\section{a) 周産期予後}

\begin{tabular}{|c|c|c|c|c|c|c|}
\hline & & $\begin{array}{l}\text { 分娭数 } \\
(n=64)\end{array}$ & $\begin{array}{l}\text { 割合 } \\
(\%)\end{array}$ & & $\begin{array}{l}\text { 分娭数 } \\
(n=64)\end{array}$ & $\begin{array}{l}\text { 割合 } \\
\text { (\%) }\end{array}$ \\
\hline \multirow{2}{*}{\multicolumn{2}{|c|}{ 正期産 }} & \multirow{2}{*}{58} & \multirow{2}{*}{91} & 帝王切開 & 63 & 98 \\
\hline & & & & 経腔分娘 & 1 & 2 \\
\hline \multicolumn{2}{|l|}{ 早産 (33-36䓢) } & \multirow{6}{*}{6} & \multirow{6}{*}{9} & & & \\
\hline preterm PROM & 1例 & & & & & \\
\hline 妊姫高血压在 & 1 例 & & & & & \\
\hline 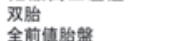 & 1 㒛 & & & & & \\
\hline 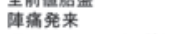 & 1 例 & & & & & \\
\hline silent rupture (双胎) & 19 & & & & & \\
\hline
\end{tabular}

算出を行っている。また、分婏に至った症例の中 には死産分婏はなかった（表 3 ）。

分婏に至った64例の周産期予後と分娩予後を表 4 にまとめた。正期産は $91 \%$ （58/64）早産は $9 \%$ （6/64）だった。早産は33週から36週での出産で あり、児に異常は認めなかった。早産の適応は、 preterm PROM、妊娠高血圧症、双胎、出血を 伴う全前置胎盤、陣痛発来、silent ruptureがそ れぞれ 1 例ずつであった。Silent ruptureの症例 で認めた子宮破裂の部位は、核出した筋腫の位置 とは異なる部位であり、LMが原因であるかどう かは不明であった。分娩方法は帝王切開が98\%
（63/64）、経腟分娩が2\%（1/64）だった。

\section{【考察】}

子宮筋腫核出後の妊娠において、妊娠群では非 妊娠群と比べて有意に年齢が低いことを示す報告 が散見されるが3-4,6)、本検討においてもこれまで の報告同様に年齢が妊娠に最も寄与する因子と考 えられた。またDessolle Lら ${ }^{3)} 、$ Vercellini $\mathrm{P}{ }^{6)}$ は妊娠群において有意に術前不妊期間が短いと報 告しているが、我々の検討においても術前不妊期 間が妊娠に影響している可能性が示唆された。本 検討における単変量解析では、妊娠群と非妊娠群 において、筋腫核出個数や筋腫重量、筋腫最大径 との関連はないにも関わらず、子宮内膜症合併率 と手術時間に有意差を認めた。これは子宮筋腫核 出ではなく、子宮内膜症が不妊と関連しているこ とを示唆すると同時に、子宮内膜症自体が手術時 間の延長にも寄与している可能性が考えられる。 しかし、今回の検討では対象を不妊患者と限定し ていないため、筋腫 - 子宮内膜症と不妊との明確 な関連性を示すことはできない。

LM後の妊娠率については37-55\% ${ }^{34,7,8)}$ と文献に より幅がある。今回の我々の検討における妊娠率 は $58 \%$ と他の報告と比較するとやや高い傾向にあ った。また生児獲得率は67-86\%、流産率は14$27 \%$ との報告 $34.7,7)$ に比べ、当院ではそれぞれ $70 \% 、 28 \%$ であり、生児獲得率は同等であるもの の、流産率は高い傾向にあった。これは我々の検 討では自然妊娠率が低く、体外受精率が高く、ま た平均年齢が高い傾向にあることも要因と考えら れる。分婏方法については施設により帝王切開率 が異なることがわかるが (表 5 )、当院ではLM

表 5 文献で報告されるLM後の妊娠予後

\begin{tabular}{|c|c|c|c|c|c|c|}
\hline & $\begin{array}{c}\text { 妊娠率 } \\
(\%)\end{array}$ & $\begin{array}{c}\text { 生児獲得率(\%) } \\
\text { (生児数/総妊娠回数) }\end{array}$ & $\begin{array}{c}\text { 流産 } \\
\text { 率 } \\
(\%)\end{array}$ & $\begin{array}{c}\text { 妊娠形態 } \\
(\%)\end{array}$ & $\begin{array}{l}\text { 年齢 } \\
\text { (歲) }\end{array}$ & 分娩方法 \\
\hline Present study & $\begin{array}{c}58 \\
(88 / 153)\end{array}$ & $\begin{array}{c}70 \\
(64 / 92)\end{array}$ & 28 & $\begin{array}{c}\text { 自然 } 66 \\
\text { IUI } 7 \\
\text { IVF-ET } \\
26\end{array}$ & $36.1 \pm 3.6$ & $\begin{array}{c}\text { Vaginal } 2 \% \\
\text { C/S } 98 \%\end{array}$ \\
\hline Dessolle L et al. ${ }^{3)}$ & 41 & 86 & 14 & $\begin{array}{c}\text { 自然 } 81 \\
\text { IUI } 5 \\
\text { IVF-ET } \\
14\end{array}$ & - & $\begin{array}{c}\text { Vaginal } 77 \% \\
\text { C/S } 29 \%\end{array}$ \\
\hline Soriano D et al. ${ }^{7}$ & 42 & 82 & 19 & $\begin{array}{c}\text { 自然 } 82 \\
\text { IUI } 5 \\
\text { IVF-ET } \\
13\end{array}$ & - & $\begin{array}{c}\text { Vaginal } 77 \% \\
\text { C/S 24\% }\end{array}$ \\
\hline Kumakiri $\mathrm{J}$ et al. ${ }^{4)}$ & 37 & 68 & 23 & $\begin{array}{l}\text { 自然 } 85 \\
\text { ART } 15\end{array}$ & $34.5 \pm 3.2$ & $\begin{array}{c}\text { Vaginal } 59 \% \\
\text { C/S } 41 \%\end{array}$ \\
\hline Seracchioli R et al. ${ }^{8)}$ & 55 & 67 & 27 & $\begin{array}{c}\text { 自然 } 97 \\
\text { IUI } 1 \\
\text { IVF-ET } 2\end{array}$ & $33.7 \pm 3.6$ & $\begin{array}{c}\text { Vaginal } 26 \% \\
\text { C/S } 75 \%\end{array}$ \\
\hline
\end{tabular}


後は子宮破裂のリスクを避けるために基本的に帝 王切開を施行する方針となっているため、他の報 告と比べても明らかに高い帝王切開率となってい る。当院でLMを施行し他院で分娩をする際にも 帝王切開を推奨しているが、最終的な分娩方法は 施設の方針により決定される。しかし本検討では 他院で分婏した症例は全て帝王切開術が選択され ていた。また、当院ではLM後の経腟分婏に対し て特定の施設基準を設けてはいないが、筋層への 切開をほとんど行っていない症例に限り術者の判 断により経腟分娩を許可している。その際には他 院で分娩する場合にも経腟分婏で問題ない旨を転 院先へ伝えている。

本検討の異所性妊娠率は $1 \%$ だが、約 $2 \%$ とさ れる過去の報告と比べて低い傾向だった ${ }^{9)}$ 。また silent ruptureの症例を 1 例認めたが、破裂部位 は筋腫を核出した部位とは異なりLMが原因であ るかどうかは不明であった。子宮破裂の頻度につ いてはLM後 : 0.5-1.0\%、開腹筋腫核出後 : 0.2$4.4 \%$ と報告されている ${ }^{5.810)}$ 。LMの方が開腹と比 較して子宮破裂の頻度が増加するというエビデン スもないが、これまでに報告されているLM後の 子宮破裂の症例を当院の症例も含めて表 6 にまと めた。諸家の子宮破裂の報告では核出した筋腫の 個数は $1-3$ 個と少なく、筋腫径も $1-5 \mathrm{~cm}$ と 小さいものが多く認められ、漿膜下筋腫と筋層内 筋腫である。縫合方法としては細い糸による 1 層 縫合や漿膜のみの縫合などもあり、さらに縫合し ていない症例も認められる。また止血には縫合を 用いずモノポーラやバイポーラのエネルギーデバ
イスのみしか使用していない症例もある。Parker ら ${ }^{5)}$ は、こうした手術手技は開腹子宮筋腫核出術 の標準術式とは明らかに逸脱しており、破裂の原 因となる可能性について指摘している。LM後の 子宮破裂の危険因子の 1 つとして、筋腫核出後か ら妊娠までの期間が短いことを仮説として述べて いる報告もあり ${ }^{18,19)}$ 、切開層の治癒が不完全な状 態のままであることを理由として挙げている。し かしこれまでにこの仮説を支持するデー夕は得ら れていない。表 6 の症例では術後から妊娠までの 期間は半年以内の症例もあるが、 7 年後に破裂し た症例もあり、子宮破裂と術後から妊娠に至まで の期間に明らかな相関性は見出せない。子宮破裂 が起る時期では、妊娠後期に起ることが多いが、 妊娠中期で起こす症例も報告されている。これら の症例報告と比較しても本検討における silent ruptureの原因は明確にはならないが、頻度は低 いもののLM後の妊娠において子宮破裂は起こり 得るということを常に念頭におき、定期的な超音 波検査による注意深い評価を施行していくことが 望ましいと考えられる。

\section{【結 論】}

本検討において、LM後の妊娠に寄与する因子 として年齢が関連していた。腹腔鏡下子宮筋腫核 出術は周産期予後を悪化させないと考えられる。

本論文の要旨は第 51 回日本産科婦人科内視鏡学 会において発表した。

表 6 LM後子宮破裂の文献報告

\begin{tabular}{|c|c|c|c|c|c|c|c|}
\hline & $\begin{array}{l}\text { 核出個数 } \\
\text { (個) }\end{array}$ & $\begin{array}{l}\text { 筋睡径 } \\
(\mathrm{cm})\end{array}$ & 筋腫の種類 & 縫合方法 & 止血方法 & $\begin{array}{c}\text { 妊娠まで } \\
\text { の期間 } \\
\text { (月) }\end{array}$ & $\begin{array}{l}\text { 破裂の } \\
\text { 週数 } \\
\text { (週) }\end{array}$ \\
\hline Present Study & 9 & $0.5 \sim 4$ & $\begin{array}{l}\text { 籃層内 } \\
\text { 槳膜下 }\end{array}$ & $\begin{array}{c}\text { 1 2層 } \\
\text { 0-モノクルル }\end{array}$ & バイポーラ & 3 & 35 \\
\hline Harris et al. ${ }^{11}$ & 1 & 3 & 腺膜下 & $\begin{array}{c}\text { 槳膜のみ } \\
4-0 \text { ポリフィラメント }\end{array}$ & モノポーラ & 3 & 34 \\
\hline Pelosi MA $3^{\text {rd }}$ et al. ${ }^{12)}$ & 1 & 5 & 槳膜下 & なし & パイポーラ & 36 & 33 \\
\hline Parker WH et al. ${ }^{13)}$ & 1 & 11 & 有莰性漿膜下 & なし & モノポーラ & 84 & 17 \\
\hline Foucher $\mathrm{F}$ et al. ${ }^{14)}$ & 3 & $1 \sim 3$ & 壯膜下 & なし & - & 60 & 31 \\
\hline Hasbargen $\mathrm{U}$ et al. ${ }^{15)}$ & 2 & 1.2 & 有茎性墏膜下 & なし & モノポーラ & 3 & 29 \\
\hline Banas T et al. ${ }^{16)}$ & 1 & 4 & 筋層内 & 8の字縫合(1針) & パイポーラ & 36 & 35 \\
\hline Asakura $\mathrm{H}$ et al. ${ }^{17)}$ & 1 & - & 筋層内 & - & - & 5 & 35.5 \\
\hline
\end{tabular}




\section{【引用文献】}

1) Downes E et al. The burden of uterine fibroids in five European countiries. Eur J Obstet Gynecol Reprod Biol. 2010; 152: 96-102.

2) Pritts EA, Parker WH, Olive DL.: Fibroids and infertility: an updated systematic review of the evidence. Fertili Steril. 2009; 91: 1215-1223.

3 ) Dessolle L et al.: Determinants of pregnancy rate and obstetric outcome after laparoscopic myomectomy for infertility. Fertili Steril. 2001; 76: 370-374.

4) Kumakiri J et al.: Pregnancy and delivery after laparoscopic myomectomy. J Minim Invasive Gynecol. 2005; 12: 241-246.

5 ) Parker WH et al.: Rsik factors for uterine rupture after laparoscopic myomectomy. J Minim Invasive Gynecol. 2010; 17: 551-554.

6) Vercellini P et al.: Determinants of reproductive outcome after abdominal myomectomy for infertility. Fertili Steril. 1999; 72: 109-114.

7) Soriano D et al.: Pregnancy outcome after laparoscopic and laparoconverted myomectomy. Eur J Obstet Gynecol Reprod Biol. 2003; 108: 194198.

8 ) Seracchioli R et al.: Obstetric and delivery outcome of pregnancies achived after laparoscopic myomectomy. Fertili Steril. 2006; 86: 159-165.

9 ) F. Cunningham et al.: Williams Obstetrics. $23^{\text {rd }}$ Edition. Chapter 10. Ectopic pregnancy. 2010; 238256. Mc Graw Hill.

10) Dubuisson JB et al.: Pregncncy outcome and deliveries following laparoscopic myomectomy. Hum Reprod. 2000; 15: 869-873.

11) Harris WJ.: Uterine dehiscence following laparoscopic myomectomy. Obstet Gynecol. 1992; 80: 545-546.

12) Pelosi MA 3rd, Pelosi MA.: Spontaneous uterine rupture at thirty-three weeks subsequent to previous superficial laparoscopic myomectomy. Am J Obstet Gynecol. 1997; 177: 1547-1549.

13) Parker WH, Iacampo K, Long T. : Uterine rupture after laparoscopic removal of a pedunculated myoma. J Minim Invasive Gynecol. 2007; 14: 362-364.

14) Foucher $\mathrm{F}$ et al:: Uterine rupture during pregnancy following myomectomy via coelioscopy. Eur J Obstet Gynecol Reprod Biol. 2000; 92: 279-281.

15) Hasbargen $U$ et al.: Uterine dehiscence in nullipara, diagnosed by MRI, following use of unipolar electrocautery myomectomy: Case report. Hum Reprod. 2002; 17: 2180-2182.

16) Banas $\mathrm{T}$ et al.: Spontaneous uterine rupture at 35 weeks' gestation, 3 years after laparoscopic myomectomy, without signs of fetal distress. J
Obstet Gynecol Res. 2005; 31: 527-530.

17) Asakura $\mathrm{H}$ et al.: A case report: change in fetal heart rate pattern on spontaneous uterine rupture at 35 weeks gestation after laparoscopically assisted myomectomy. J Nihon Med Sch. 2004; 71: 69-72.

18) Seinera $P$, Farina $C$, Todros T.: Laparoscopic myomectomy and subsequent pregnancy: results in 54 patients. Hum Reprod. 2000; 15: 1933-1936.

19）木村秀崇、他: 腹䏶鏡下筋腫核出術後の妊産婦管理、 産婦人科治療、2006；92:276-279. 